Pol. Con. (Edición núm. 6) Vol. 2, No. 4

Abril 2017, pp. 92-100

ISSN: 2550 - 682X

DOI: $10.23857 / p c . v 2 i 4.57$

Recepción: 01 / 12 / 2016

Aceptación: 23/ 03 / 2017

Publicación: 29 / 04 / 2017

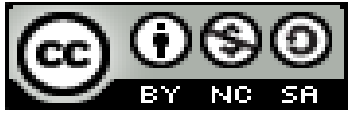

Ciencias de la salud

Artículo de investigación

\title{
Consideraciones generales acerca de la xerostomía en pacientes con prótesis dental
}

\section{General Considerations About the Xerostomia of the Patients with Dental Prótesis}

\section{Considerações sobre a xerostomia em pacientes com próteses}

\author{
Freya M. Vera-Andrade \\ fretaveraandrade@gmail.com
Alcira M. Solórzano-Alvarado ${ }^{\mathrm{II}}$
alcirasolorzano@gmail.com \\ Sandra Sandoval-Pedauga III \\ sansrasandovalp@hotmail.com
}

Correspondencia: fretaveraandrade@gmail.com

\footnotetext{
I Especialidad en Periodoncia, Odontóloga, Docente de la Universidad Laica Eloy Alfaro de Manabí, Manta, Ecuador.

II Magister en Gerencia y Auditoria de Servicios de Salud Bucal, Odontóloga, Docente de la Universidad Laica Eloy Alfaro de Manabí, Manta, Ecuador.

III Odontóloga, Especialista en Rehabilitación Oral, Docente de la Universidad Laica Eloy Alfaro de Manabí, Manta, Ecuador.
} 


\section{Resumen}

Teniendo en cuenta que la Federación Dental Internacional (FDI) define este síndrome como "la enfermedad del hombre moderno", debido a su carácter casi epidémico, ya que afecta a una de cada cuatro personas y que aumenta a partir de los cincuenta años. A tales efectos, se realizó una revisión bibliográfica exhaustiva, con el objetivo de obtener una información actualizada sobre el comportamiento de la xerostomía en los individuos que usan prótesis dental; se analizan algunos aspectos de interés, tales como: epidemióloga, etiología, clínica y los trastornos que ocasiona la sequedad bucal para el soporte y funcionamiento de las prótesis, entre otros. Se concluye que el conocimiento de la xerostomía ayudará a realizar un diagnóstico precoz y su tratamiento eficaz para evitar las complicaciones en pacientes que usan prótesis dental

Palabras clave: prótesis dental, saliva, xerostomía.

\section{Abstract}

Taking into account that the International Dental Federation (IDF) defines this syndrome as "the disease of modern man" because of its almost epidemic character, since it affects one in four people and increases from the age of fifty. To that end, a comprehensive bibliographic review was carried out with the objective of obtaining updated information on the behavior of Xerostomia in individuals using dental prosthesis. Some aspects of interest are analyzed, such as: epidemiologist, etiology, clinic and the disorders it causes Dry mouth for the support and operation of prostheses, among others. It is concluded that knowledge of xerostomia will help to make an early diagnosis and its effective treatment to avoid complications in patients using dental prostheses.

Key words: dental prosthesis.saliva, xerostomia.

\section{Resumo}

Dado que a Federação Dentária Internacional (FDI) define a síndrome como "doença do homem moderno" por causa de seus quase proporções epidêmicas, afetando uma em cada quatro pessoas e aumenta a partir dos anos cinquenta. Para este fim, uma revisão da literatura abrangente foi realizado, a fim de obter uma atualização sobre o comportamento de xerostomia em indivíduos que usam dentaduras informação; epidemiologia, etiologia, clínica e distúrbios que causam boca 
seca para o suporte e operação da prótese, incluindo: alguns aspectos de interesse, tais como são discutidos. Conclui-se que o conhecimento da xerostomia ajuda diagnóstico precoce e tratamento eficaz para prevenir complicações em pacientes em uso de próteses dentárias

Palavras chave: dentaduras, saliva, xerostomia

\section{Introducción}

La presencia de saliva en la cavidad oral es muy importante porque gracias a ella se mantienen humectados los tejidos orales, facilitando el habla, la masticación, la deglución, etcétera. La saliva también permite la función de limpieza de la boca, así como la regulación de la acumulación de bacterias. Un nivel de saliva adecuado puede evitar un desequilibrio de microorganismos en el ambiente oral, que puede dar paso a la aparición de caries, enfermedades en las encías, halitosis o mal aliento, entre otras. ${ }^{1}$

La saliva está compuesta por una mezcla de enzimas, reguladores, anticuerpos y nutrientes que actúan contra los organismos patógenos, aunque también es un aliado fundamental en el proceso de trabajo de los dientes y de las encías. ${ }^{1}$

Además de esta función digestiva y antibacteriana, la saliva también se compone de iones minerales, especialmente de calcio y fosfato, que son los ingredientes de los que se componen los dientes. De esta manera, la saliva ayuda a remineralizar los dientes y a reparar pequeñas lesiones en el esmalte. ${ }^{1}$

La xerostomía es la manifestación clínica más común de las disfunciones salivales, y consiste en una disminución de la secreción salival, denominada también boca seca, asialorrea o hiposalivación. Junfin y col. la definen como una condición clínica subjetiva, donde hay menos cantidad de saliva de lo normal, sin tener una definición entre límites normales y anormales. ${ }^{2}$

En este orden de ideas se puede citar que la xerostomía es la sensación subjetiva de sequedad bucal debido a la disminución de saliva. Puede afectar hasta a un $30 \%$ de la población general. Aunque en sí misma no es una enfermedad, altera la calidad de vida, especialmente en la población anciana. Suele recibir escasa atención, incluso por los propios médicos y, en ocasiones, el mismo paciente no lo refiere hasta que se pregunta directamente por su existencia. Sin 
embargo, puede ser el síntoma que oriente de la presencia de enfermedad sistémica, como el síndrome de Sjögren. ${ }^{3}$

Según se ha citado, la xerostomía se manifiesta en uno de cada cinco adultos, lo que equivale al $20 \%$ de la población de entre 18 y 30 años, y a un $40 \%$ en los mayores de 50 años. Afecta el doble a mujeres que a hombres. Según datos estadísticos, la xerostomía cada vez va tomando un mayor protagonismo en la sociedad; es una condición que altera la salud general y la calidad de vida. $^{4}$

En la población en edad geriátrica, la xerostomía es un síntoma frecuente, pero no debe considerarse simplemente como expresión del envejecimiento, ya que las causas también son múltiples. En el estudio de Sreebny et al., donde se analizó la presencia de xerostomía en población general, la prevalecía fue mayor en el grupo de más de 55 años de edad (40 \%), pero también presentaba xerostomía el $20 \%$ del grupo entre los 18 a 34 años, y en el $26 \%$ en el grupo entre 35 a 54 años de edad. En este estudio, sólo el 54 \% de los que tenían xerostomía mostraron un flujo basal no estimulado patológico $(<1,5 \mathrm{~mL}) .^{3}$

\section{Etiología de la xerostomía}

La xerostomía, aunque no es considerada como una enfermedad, puede implicar la presencia de alteraciones relacionadas directamente con las glándulas salivales o ser el resultado de trastornos sistémicos. Entre las causas de la xerostomía podemos incluir el uso de medicamentos, terapias oncológicas (radiación o quimioterapia), terapia quirúrgica, alteraciones psicológicas, enfermedades autoinmunes ${ }^{2}$. Estos factores modifican la secreción del flujo salival por diferentes mecanismos que incluyen la interrupción de la función de nervios autónomos, interferencias con las células ductales o acinares de las glándulas salivales, citotoxicidad, efectos indirectos (vasoconstricción o vasodilatación, balance de fluidos y electrolitos) y trauma físico a las glándulas salivales y nervios. ${ }^{2}$

Sin embargo, la humedad bucal no solo depende de la glándula salival, sino influyen otros aspectos como la inervación neurológica que interviene en los mecanismos de secreción salivar, los propios componentes de la saliva que proporcionan la adecuada viscosidad y la función normal del sistema nervioso central como elemento integrador. ${ }^{3}$ 


\section{Clínica}

La xerostomía se presenta con la sensación consciente de la falta de saliva o de humedad bucal, bien de forma basal o cuando se precisa un aumento de la producción de saliva, por ejemplo al hablar. Según el grado de afección podemos encontrar signos y síntomas característicos, como aparición de un enantema difuso de la mucosa bucal, pérdida de su brillo característico o una notable depapilación lingual, disgeusia, disestesias, descamación labial, caries y enfermedad periodontal; trastornos en deglución y fonación, y dificultades en el uso de las prótesis dentales. El paciente refiere sed y además existe una predisposición al desarrollo de candidiasis. ${ }^{3}$

Varias investigaciones han demostrado que las prótesis, sobre todo cuando son viejas, desajustadas, incorrectamente confeccionadas o están en mal estado, producen daños que junto a inadecuados estilos de vida, contribuyen aun más al deficiente estado de la cavidad bucal y afectan, en todos los aspectos, la salud de las personas, principalmente en los ancianos. ${ }^{5,6}$

\section{Evaluación del paciente con xerostomía}

El odontólogo debe observar ciertos signos al realizar el examen clínico como: desprendimiento de parte del epitelio de la mucosa al remover los rollos de algodón de la boca; los dedos de los guantes o los instrumentos tienden a adherirse a los tejidos bucales del paciente; algunos problemas con las prótesis, no pueden ser atribuidos a fallas en el diseño o construcción de las mismas; presencia de caries recurrentes y en zonas donde su aparición es poco frecuente. ${ }^{2}$

\section{Efectos de la xerostomía}

Uno de los primeros cambios que ocurren en la boca con xerostomía, es que la saliva se observa espumosa y aumenta la viscosidad de la misma, y sus efectos sobre los tejidos blandos y duros de la cavidad bucal pueden ser observados. ${ }^{2}$

La prevalecía de la xerostomía se sitúa en cerca del $40 \%$ en mayores de 60 años, según investigaciones. La sequedad bucal es un problema común en el anciano, principalmente como consecuencia del gran número de medicamentos usados (alta frecuencia de polifarmacia), la ausencia de dientes y alimentación blanda con escasa o ausencia de masticación. La sequedad bucal está relacionada con la edad y fuertemente relacionada también con el curso de la farmacoterapia. ${ }^{7}$ 
En igual forma, la xerostomía puede aumentar la severidad de los síntomas asociados a la estomatitis, también puede llevar a las dificultades en los tratamientos de los pacientes protésicos, ya que el ajuste y retención de dentaduras postizas removibles dependen grandemente de la lubricación de la mucosa por la saliva, que pueden ayudar a la retención de prótesis. Además, el flujo de saliva facilita la masticación, formación de bolos de comida y deglución, y juega un papel importante en la articulación y el habla ${ }^{7}$. Los pacientes que presentan una mucosa bucal no resiliente, delgada con poco reborde y además presentan xerostomía crónica, se les debe indicar prótesis con bases blandas. ${ }^{7}$

En el orden de las ideas anteriores se debe estar atento tanto con el paciente que acude por primera vez a recibir atención, como el que ya ha usado prótesis previamente y refiere alguna sintomatología, realizando un diagnóstico que detecte la presencia de este síndrome, y ser capaz de tratarlo de forma preventiva y curativa para disminuir males mayores. ${ }^{7}$

Algunos autores plantean que dentro de las quejas más comunes del paciente con xerostomía son: sensación de sequedad y ardor en boca y garganta, molestias al utilizar las prótesis, necesidad de ingerir líquidos frecuentemente, la comida se queda adherida a las mucosas y dientes, las obturaciones se caen con facilidad y aumenta el índice de caries. ${ }^{7}$

El uso de dentaduras parciales removibles o dentaduras totales son una experiencia desagradable para el paciente con xerostomía, ya que la falta de saliva reduce la retención de las prótesis, por lo que se recomienda al paciente que no las usen durante la noche, las laven con jabón y las sumerjan en agua. Además, se aconseja la colocación de un agente antimicótico, cada vez que las usen y se enjuaguen la boca después de cada comida. ${ }^{7}$

La revisión y realización de cualquier tratamiento son importantes para el éxito. Los pacientes con xerostomía deben interiorizar la importancia del examen bucal frecuente para prevenir el desarrollo de enfermedades, por lo que debe examinarse cada tres meses, al menos la primera vez y prolongarse después, según la respuesta al tratamiento. ${ }^{7}$

En los pacientes con xerostomía el tratamiento protésico es desafiante y el éxito depende del conocimiento de los problemas particulares y métodos de prevención combinado con un protesista hábil, por lo que a los pacientes que acudan a los servicios odontológico se les debe 
interrogar acerca de la percepción de xerostomía y del uso de medicamentos antes del tratamiento, ya sea preventivo, curativo o ambos. ${ }^{7}$

\section{Lesión en prótesis removibles}

En los pacientes portadores de prótesis removibles (dentaduras postizas), la falta de la lubricación mucosa crea diferentes problemas. Estos pacientes tienen cierta dificultad en retener la prótesis en su posición y usarlas de forma correcta. Esto facilita la aparición de erosiones y ulceraciones de las mucosas, las cuales son muy dolorosas y pueden infectarse fácilmente.

Según F. Nikolopoulou, en su investigación acerca de la prevalecía de la xerostomía en pacientes con prótesis removibles, concluyó que había era muy elevada, y una gran proporción de los pacientes mostraba una escasa higiene oral. ${ }^{8}$

En pacientes que usan prótesis se describen lesiones frecuentes como la estomatitis subprótesis y entre otros, signos y síntomas como ardor, dolor, mal gusto, halitosis, inflamación, infección por Candida albicans, que de forma común aparecen descritos en pacientes con xerostomía. Este síndrome podría ser un factor importante en la aparición de la estomatitis subprótesis y otras lesiones frecuentes en pacientes que usan prótesis, al no estar presente la protección salival. ${ }^{7}$

Otros investigadores señalan que los tejidos bucales sufren alteraciones de la colágena, y es probable que su capacidad de regeneración vaya menguando durante el proceso de envejecimiento, debido a la disminución del área de soporte de la prótesis, provocado por la destrucción alveolar (después de las extracciones dentarias), así como por la disminución de la secreción salival. ${ }^{7}$

En la mayoría de las bibliografías consultadas sobre xerostomía, se plantea que los individuos que presentan el síndrome y usan prótesis tienen dificultad con el uso de ella, en relación con el adecuado ajuste y retención, además de que en general aparecen dificultades para hablar, masticar, tragar y saborear los alimentos, que conllevan a trastornos de nutrición, por lo que se afecta su salud bucal, su salud general y, por tanto, su calidad de vida.

Se han diseñado prótesis dentales totales con reservorios de saliva artificial en su estructura. Hirvikangas y col. realizaron algunas modificaciones en las prótesis totales para dar espacio a la colocación de reservorios con saliva artificial. Obtuvieron éxito sólo en la dentadura maxilar, ya 
que en las dentaduras inferiores el segmento posterior se separaba de la base durante la masticación. $^{7}$

\section{Conclusiones}

Para el odontólogo es importante reconocer esta condición realizando un apropiado diagnóstico del paciente con "Síndrome de boca seca" o xerostomía, investigar su etiología y determinar la capacidad secretora de las glándulas salivales, todo esto con el propósito de aplicar el tratamiento más adecuado para el paciente portador de prótesis.

\section{Referencias bibliográficas}

1- Pardiñas López, L. La saliva y su importancia en la salud. 2012. [citado 11 octubre 2016]. Disponible en: http://www.clinicapardinas.com/la-saliva-y-su-importancia-en-lasalud.htm

2- Valicena, M.; Escalona, L. A. Manejo terapeútico del paciente con xerostomía. 2001. [citado 11 octubre 2016]. Acta odontológica venezolana 39(1). Disponible en: http://www.actaodontologica.com/ediciones/2001/1/manejo_terapeutico_paciente_xerosto mia.asp

3- Un paciente con xerostomía. 2016 [citado 11 octubre 2016]. Disponible en: www.elsevier.es/esrevista-medicina-integral-63-pdf-11000252-S300

4- Xerostomía boca seca. [citado 11 octubre 2016]. Disponible en: http://www.dentaid.es/es/xerostomia

5- Sáez Carriera, R.; Carmona, M.; Jiménez Quintana, Z.; Alfaro, X. “Cambios bucales en el adulto mayor". Rev. Cubana Estomatol. 2007 [citado 11 octubre 2016]; 44(4):15 p. Disponible en: http://scielo.sld.cu/scielo.php?script=sci_arttext\&pid=S003475072007000400011\&lng=es\&nrm=iso\&tlng=es [Buscar en Google Scholar]

6- Mulet García, M.; Reigada de Santelice, A.; Espeso Nápoles, N. "Salud bucal en pacientes portadores de prótesis. Impacto de una estrategia educativa". Revista Archivo Médico de Camagüey. 2006 [citado 11 octubre 2016]; 10(3): 4. Disponible en: http://www.amc.sld.cu/amc/2006/v10n3-2006/2064.htm 
7- Rodríguez Palacios, A.; Martínez Naranjo, T. La xerostomía en pacientes con prótesis dental. [citado 11 octubre 2016]. Disponible en: http://www.bvs.sld.cu/revistas/est/vol45_2_08/est10208.htm

8- Nikolopoulou, Theodoros; Tasopoulos, Robert Jagger. "Prevalecía de la xerostomía en pacientes con prótesis removibles". Revista internacional de prótesis estomatológica, 2014 [citado 11 octubre 2016]; págs. 145-147. Disponible en: https://dialnet.unirioja.es/servlet/articulo?codigo $=4918510$ 